\title{
Stalled on the Roadmap? The Status of Cultural and Linguistic Competence-related Policies that Impact Children's Mental Health in the United States
}

\section{Janice $L$ Cooper ${ }^{1}$ and Yumiko Aratani ${ }^{2 *}$}

${ }^{1}$ Department of Health Policy and Management, Rollins School of Public Health, Emory University, USA

${ }^{2}$ Columbia University Mailman School of Public Health, National Center for Children in Poverty, USA

\begin{abstract}
There are acknowledged disparities in access to quality children's mental health services and in outcomes based on race/ethnicity and English language proficiency in the United States. To assess how states currently make operational key principles of cultural and linguistic competence and to assess barriers, we surveyed United States state child mental health directors on their policylinked strategies to increase cultural and linguistic competence and reduce disparities. Based on previous research, strategies to address system-level challenges were identified. They included: the existence of cultural advisory bodies, implementation of a cultural competence plan, workforce development, measurement and self-assessments and leadership. Forty states participated in the survey. Our findings indicate that state-led efforts remain limited. Only seven states had updated strategic plans, and eleven reported having regular assessments on disparities. Twenty-three states reported implementing cultural and linguistic competence training for providers. States face numerous barriers to their efforts to devise and implement policy-linked strategies to reduce disparities. With the Affordable Care Act of 2010 and the enhanced national standards for culturally and linguistically appropriate services in health and health care, states should advance policy to address disparities in children's mental health based on race/ethnicity and English language proficiency.
\end{abstract}

Keywords: Child public health; Mental health; Cultural and linguistic competence; Racial and ethnic disparities

\section{Introduction}

For decades, researchers and policy makers have acknowledged disparities in access to quality children's mental health services based on race/ethnicity and language [1]. While some states may have made progress in implementing policy changes aimed at reducing disparities, much work remains. Released over 20 years ago, Towards a Culturally Competent System of Care provided a roadmap to reform the child mental health field [2]. This landmark document laid out principles necessary to guide efforts to reduce disparities in service delivery based on racial, ethnic and cultural factors. More recently, language access has emerged as a key feature in improving mental health care for children and youth [3]. This paper presents results from a study of states' adoption of key policy-related strategies designed to reduce disparities and increase cultural and linguistic competence in child mental health services in the United States. Respondents were child mental health leaders with direct knowledge of policies related to cultural and linguistic competence.

Children with behavioral problems are less likely to receive services they need. Even when diagnosed with mental health conditions, children from diverse racial/ethnic backgrounds are less likely to receive services [4] Access to services and its quality can be further compromised for children and youth with limited English proficiency [5]. Children from racially and ethnically diverse background are less likely to access effective treatment and often experience poorer outcomes even with treatment [1,6-8]. Children and youth with limited English proficiency are also more likely to drop out from services even if they access care [9]. Continuing evidence indicates policy changes are needed to address disparities in health care access, treatment and outcomes. Research suggests that the development and implementation of macro-level policies and more targeted strategies may be more effective, despite the inherent challenges $[10,11]$. While research points to specific policy solutions, disparities have persisted [12-16]. The President's New Freedom Commission on Mental Health (The President's New Freedom Commission on Mental Health 2003) recommended that states take initiatives on these policy solutions. The problem has been how to design culturally and linguistically competent policies that are also associated with improved outcomes. By looking at the sources of barriers to health care, researchers identified socio-cultural barriers among the factors that contribute to disparities in access and outcomes. Specific elements include: a) organizational and workforce related obstacles to care; b) structural challenges; and, c) clinical barriers [17]. We classified those as system-level and stakeholder (youth service users and family members)-level challenges.

\section{System-level challenges}

The system-level challenges include organizational and workforce related problems. Survey data and numerous government reports documented the shortage of providers and support workers with similar racial/ethnic and linguistic backgrounds to the children and youth they serve [18]. Research also pointed to the impact of provider-patient relationships on health care quality and outcomes. This knowledge suggests an avenue to address organizational and workforce related challenges in the delivery of child mental health care [19].

\section{Stakeholders-level challenges}

Barriers to mental health care, such as lack of transportation, long waiting lists and lack of insurance are a reality for stakeholders who consist of individual youth service users and their family members. These barriers are experienced irrespective of race/ethnicity and English proficiency [20-22]. Yet, research demonstrates the increased impact for individuals without access to culturally and linguistically competent materials, or who lack knowledge or belief in the validity of

*Corresponding author: Yumiko Aratani, Acting Director, Health and Mental Health, Associate Research Scientist, Columbia University Mailman School of Public Health, National Center for Children in Poverty, $215 \mathrm{~W} 125^{\text {th }}$ street, $3^{\text {rd }}$ floor, New York, NY 10027, USA, Tel: 646-284-9642, Fax: 646-284-9623; E-mail: ya61@ columbia.edu

Received October 23, 2013; Accepted December 11, 2013; Published December 23, 2013

Citation: Cooper JL, Aratani Y (2013) Stalled on the Roadmap? The Status of Cultural and Linguistic Competence-related Policies that Impact Children's Mental Health in the United States. Primary Health Care 3: 143. doi:10.4172/21671079.1000143

Copyright: (c) 2013 Cooper JL, et al. This is an open-access article distributed under the terms of the Creative Commons Attribution License, which permits unrestricted use, distribution, and reproduction in any medium, provided the original author and source are credited. 


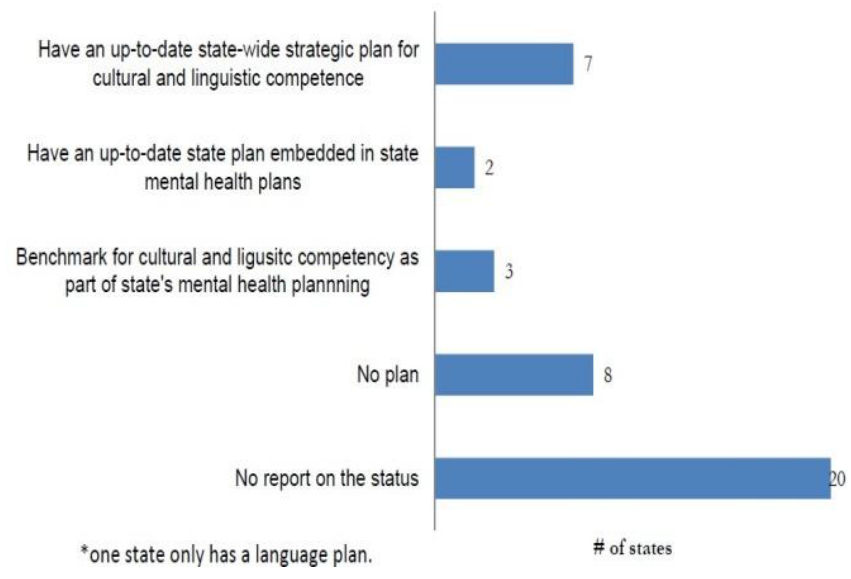

Figure 1: Status of implementation of a statewide cultural and linguistic competence plan.

mental health interventions [23]. It also includes clinical barriers such as the failure to apply evidence of the impact of cultural and linguistic diversity in sustaining engagement in treatment [24].

To assess how states currently make operational key principles of cultural and linguistic competence and to assess barriers, we conducted a web-based survey of state mental health leaders. Based on previous research, strategies to address system-level challenges were identified. They included: the existence of cultural advisory bodies, implementation of a cultural competence plan, workforce development, measurement and self-assessments and leadership [17,24-26].

\section{Methodology}

Based on factors identified in the literature, the authors queried state leaders on their states' policy-linked strategies to advance cultural and linguistic competency and reduce disparities. In 2007, an invitation letter and a link to on-line survey were sent to state children's mental health directors and state multicultural directors or their representatives with expertise in mental health in 50 states, DC and 4 US territories. Two reminders were sent to increase response rates, and it resulted in having 55 responses from 40 states in total. Fifteen states had more than one respondent [10]. Respondents represented child mental health directors $(37.5 \%$, 15 of 40 states), multi-cultural coordinators $(25 \%$, 10 of 40 states), lead state policy person for addressing diversity (25\%, 10 of 40 states) and "others" (10\%, 4 of 40 states). "Others" included mental health content leaders in the State such as a Bureau Chief, content experts in cultural and linguistic competence, such as Director of Health Disparities Office and the Director of the Title V Children with Special Health Needs. Fifteen states and territories did not participate in the study. One respondent did not define their position ( $2.5 \%, 1$ of 40 states). Of the 40 participating states, approximately $45 \%$ percent reported that 50 percent or more of their portfolio was devoted to children's mental health. The study was approved by the Columbia University Medical Center Institutional Review Board (45\%, 18 of 40 states).

The study sought to determine specific policies and programmatic strategies that states implemented to: increase the level of cultural and linguistic competence in child mental health services; reduce disparities based on race/ethnicity and language access; and improve outcomes for children with mental health conditions. We asked states to identify policies that fit within the following framework: strategic planning based on assessments of need for culturally and linguistically competent services; infrastructure-related support (such as workforce development strategies including competency-based training); the designation of an individual responsible for undertaking policy-related strategies; and stakeholder involvement in policy making. All of these factors are recognized as predictors of policy implementation [27].

\section{Results}

\section{Strategic planning}

As Figure 1 shows, eight states (20\%, 8 of 40 states) had up-todate (i.e., annual or bi-annual reviews) strategic plans in place to improve cultural and linguistic competence. In two states, these plans were embedded in their states' mental health plan (5\%, 2 of 40 states). One state did not have a strategic plan for cultural and linguistic competence but indicated that the benchmarks for cultural and linguistic competence were part of the state mental health planning process and its overall strategic plan. Five states reported that their state mental health plan included benchmarks for cultural and linguistic competence ( $7.5 \%, 3$ of 40 states). Twenty states did not report on the status of state mental health and related policies on promoting cultural and linguistic competence (50\%, 20 of 40 states).

Needs assessments: In the survey, states were asked whether and how frequently, they have implemented statewide assessment of its cultural and linguistic competence. Eleven states $(27.5 \%, 11$ of 40 states) reported that they regularly conducted needs assessments, with foci ranging from assessing: disparities in access; workforce capacity; service provision in non-community based settings; and, disparities in outcomes. Only two states, California and Utah, reported that their assessments focused on disparities in outcomes, as Table 1 shows.

\section{Workforce development}

Twenty-three states $(58 \%, 23$ of 40 states) reported that they conducted provider training on cultural and linguistic competence. Of these, 19 (83\%, 19 of 23 states) reported that training was conducted either yearly or ad-hoc. Six states (26\%, 6 of 23 states) reported they provided competency-based trainings. Only one state, Colorado, conducted training that lead to certification in cultural and linguistic competence.

States also reported on other policies that supported the level of cultural and linguistic competence among the workforce. For instance, 14 states $(35 \%, 14$ of 40 states) noted that they provided policy support to recruit and retain a diverse workforce. But only six (15\%, 6 of 40 states) states provided fiscal support. Five states (13\%, 5 of 40 states) noted that their funding support was in collaboration with higher education. The most common way states supported workforce development was through specific contract language and funding requests (40\%, 15 states of 40$)$. Nine states $(23 \%, 9$ of 40 states) reported that they address credentialing and licensure in support of workforce development.

\begin{tabular}{|c|c|}
\hline Type of assessments & States \\
\hline Racial/ethnic and linguistic disparity in access/treatment & $\begin{array}{c}\mathrm{CT}, \mathrm{FL}, \mathrm{MA}, \mathrm{SC}, \mathrm{UT} \\
\text { WY }\end{array}$ \\
\hline Racial/ethnic and linguistic disparity in outcomes & $\mathrm{CA}, \mathrm{UT}$ \\
\hline Workforce capacity to address racial/ethnic disparities & $\mathrm{AZ}, \mathrm{DE}, \mathrm{OR}$ \\
\hline $\begin{array}{c}\text { Disproportional representation of racial/ethnic and } \\
\text { linguistic children and youth in non-community based } \\
\text { settings }\end{array}$ & MT \\
\hline
\end{tabular}

Table 1: Type of state-wide annual or semi-annual assessments of cultural and linguistic competence. 


\begin{tabular}{|c|c|c|}
\hline Policy Mechanisms & $\begin{array}{c}\text { \# states reporting } \\
\text { cultural competence }\end{array}$ & $\begin{array}{c}\text { \# states reporting } \\
\text { linguistic competence }\end{array}$ \\
\hline $\begin{array}{c}\text { State legislation and } \\
\text { regulations }\end{array}$ & 15 & 11 \\
\hline $\begin{array}{c}\text { Governor's executive orders or } \\
\text { directives }\end{array}$ & 7 & 2 \\
\hline Commissioner directives & 13 & 8 \\
\hline Agency rules or regulations & 22 & 18 \\
\hline Guidelines and standards & 20 & 22 \\
\hline
\end{tabular}

Table 2: Type of state mental health and related policies that promote cultural and linguistic competence and/or elimination of racial, ethnic, cultural or linguistic disparities.

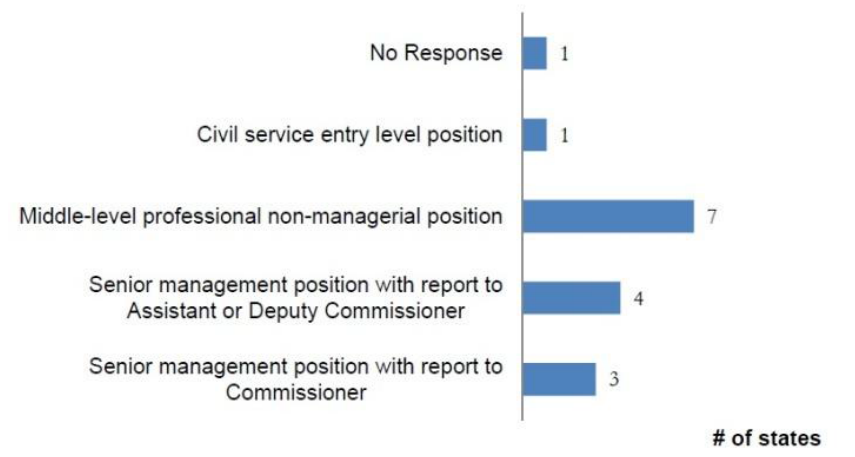

Figure 2: Rankings of designated cultural competence coordinator/similar designated person.

\section{Stakeholder engagement}

The data suggested varying levels of stakeholder responsibility for culturally and linguistically competent program and policy. Taskforces, committees, and advisory councils provided a formal mechanism for stakeholder engagement. Nineteen states $(48 \%, 19$ of 40 states) had a designated "Multicultural Task Force". Among those, 52\% (10 of 19 states) reported stakeholder input without responsibility for policy and program decision making.

\section{Legal authority}

Authority for implementation of cultural and linguistic competence fell under legislative or regulatory channels, through Executive orders or directives, Commissioner's Directors, agency rules and guidelines. Table 2 shows the types of policy and legal mechanisms that states use.

\section{Designated individual responsible for cultural and linguistic competence}

Seventeen states (40\%, 16 of 40 states), reported that a designated individual was responsible for coordinating cultural and linguistic competence-related strategies. Overall, the organizational rank of this individual was low. As Figure 2 shows, in three states, the person in this position reported to an individual at the Commissioner level.

In two states (12\%, 2 of 17 states), individuals in this position had budget-making authority (results not shown). Most states also reported that this individual, usually with the title, "multicultural coordinator", was engaged in policymaking ( $n=14$ of $17,82 \%$, results not shown).

\section{Explaining the gaps in access}

A critical component for both assessment and planning is to identify the factors that lead to gaps in access to care experienced by major racial/ethnic groups. States reported on the top three factors that contributed to gaps, shown in Table 3.
Across all racial/ethnic groups, poor provider cultural competence was identified as a major barrier. For African Americans, stigma was the top barrier, whereas for Asians and Hispanic/Latinos lack of English language proficient was the most significant. For Native Americans, structural barriers such as transportation, cost, and service location were identified barriers. State leaders identified immigration status as a major obstacle for Latinos.

\section{Discussion}

Twenty years after Towards a Culturally Competent System of Care was published, some states appeared engaged in policy efforts to improve cultural and linguistic competence in service delivery. However, these states remained in the minority. Even states with very diverse populations lacked basic elements of a systematic approach to cultural competency. They remained largely void of support for strategic planning, infrastructure, funding, and accountability mechanisms to effect meaningful policy change. The last 25 years have seen many lawsuits involving disparities in access to mental health services, yet disparities still persist [2,28-30]. The failure of governments to leverage public policies to address the needs of children and families suggests a lack of adherence to the guiding principle of health care over the last two decades: "to improve quality". For many children and youth from diverse racial/ethnic and language backgrounds and their families, appropriate mental health care remains elusive. The lack of cultural and linguistic competence in mental health service delivery for children and youth in the United States takes on added significance in light of the Affordable Care Act (ACA) and its emphasis on advancing health equality for racially and ethnically diverse populations [31]. The ACA has many provisions related to cultural and linguistic competency, and additionally the enhanced National Standards for culturally and Linguistically Appropriate Services (CLAS) in Health and Health Care was released by the Office of Minority Health in May 2013 as a resource for the ACA. There are three most important domains of the ACA provisions that are relevant to this study's findings: (1) data collection and reporting by race, ethnicity and language; (2) workforce diversity; and (3) cultural competence education and organizational support. For example, our survey results showed that less than $35 \%$ of states included regular statewide assessments of need for cultural and linguistic competence and fewer focused on outcomes. This poor emphasis on planning and system guidance through the use of empirical data suggested an ad-hoc approach to addressing cultural and linguistic competence. As part of the ACA, collection and reporting data on race, ethnicity and primary language and other demographic information are now becoming required for all federally-funded health programs and population surveys. Additionally, the Secretary of Health and Human Services (HHS) is authorized to increase efforts to monitor health disparity trends in federally-funded programs and widely disseminate the findings [31]. The strong emphasis on planning

\begin{tabular}{|c|c|c|c|}
\hline African-American & Asian American & $\begin{array}{c}\text { Hispanic/Latino } \\
\text { American }\end{array}$ & Native American \\
\hline Stigma (19) & $\begin{array}{c}\text { Language } \\
\text { barriers (17) }\end{array}$ & $\begin{array}{c}\text { Language barriers } \\
(20)\end{array}$ & $\begin{array}{c}\text { Poor provider } \\
\text { cultural competence } \\
(14)\end{array}$ \\
\hline $\begin{array}{c}\text { Poor provider } \\
\text { cultural competence } \\
(13)\end{array}$ & Stigma (16) & $\begin{array}{c}\text { Immigration Status } \\
(20)\end{array}$ & $\begin{array}{c}\text { Inadequate provider } \\
\text { capacity (14) }\end{array}$ \\
\hline $\begin{array}{c}\text { Lack of MH literacy } \\
(13)\end{array}$ & $\begin{array}{c}\text { Poor provider } \\
\text { cultural } \\
\text { competence (14) }\end{array}$ & $\begin{array}{c}\text { Poor provider } \\
\text { cultural } \\
\text { competence (13) }\end{array}$ & $\begin{array}{c}\text { Structural barriers } \\
(12)\end{array}$ \\
\hline
\end{tabular}

Table 3: Top Three gaps in access to mental health services by major racial/ethnic group (parentheses are the number of states). 
and assessment on cultural and linguistic competence would be a key to plan for new services or emerging disorders.

Second, through reauthorization and expansion of Title VII programs, the ACA can potentially improve workforce diversity in health care with appropriations. Title VII was amended to authorize $\$ 25$ million in grants to mental and health professionals with preference to historically lack higher education and institutions that serve diverse populations [31]. The striking finding of this study was the low rate of states that provided or supported workforce development through competency-based cultural and linguistic competence. While states reported that they had policies to support the creation of a diverse workforce one measure of such commitment would be through policies on recruitment and retention, yet only $35 \%$ of states reported they had such a policy and even fewer (15\%) backed up those policies with fiscal support. Third, the other domain that ACA promotes is cultural competence education and organizational support. The ACA provides five year of support for developing and disseminating model cultural competence (CC) training and education curricula, to be disseminated through online clearing house [31]. This study showed that most states do not support competency-based training for cultural and linguistic competence even though among other domains of health care such as clinical or other health care quality control training the proficiency of the workforce being trained is measured. Thus, this recent federal initiative should guide state governments to increase their capacity in promoting cultural and linguistic competence in the area of child mental health.

Additionally, leadership is a key for policy advancement. In the enhanced CLAS, a new standard 2 "advance and sustain governance and leadership that promotes CLAS and health equity" is added [32]. This new standard is developed to emphasize the importance of permeating CLAS at all aspect of organizations from top-down to bottom-up. While culturally and linguistic competency was historically a grassroots strategy. As also shown in the findings of this study, states are the weakest in terms of leadership. Only two-fifths of states designated an individual who is responsible for ensuring cultural and linguistic competence in child mental health at a state level and in only two stated does this person have any budgetary authority. The study also shows that while many states formally engaged stakeholders those processes appear can with no accountability for decision-making or holding states accountable. Indeed the results pointed to the lack of accountability for system-wide cultural and linguistic competency by not attaching ways of measuring what states do in the name of cultural competence and by not assuring an empirically-based approach. States seemed to provide vocal support for cultural and linguistic competence and give the appearance of "doing things' in the area of cultural and linguistic competence but these actions did not appear to be tied to systematic ways to embed policies so they inform sustainable practices. For example, if there were no benchmarks for planning then any actions constitute progress. If trainings are not assessed for effectiveness and the workforce is not required to be competent, then states will remain focused on outputs and the outcomes will not change. While all groups identified poor provider cultural and linguistic competence as a barrier, other barriers differed among different groups and have implications for service delivery. Stigma, language access and logistic and structural barriers pertain for African-Americans, Asians and Hispanic/Latinos and Native American respectively suggests the need for a multi-faceted approach to policy implementation.

\section{Conclusions}

Based on our findings and in light of federal efforts to be responsive to issues of equity in treatment and quality, we suggest the following policy recommendations. First, include incentives for all states to draft an up-to-date annual strategic plan to improve cultural and linguistic competence and show them how to contract through new provider mechanisms to ensure these plans are enacted. At the time of our study, less than one-fifth of states had the plan in place. Without appropriate planning, states are likely to duplicate and will be at a disadvantage in implementing the services that children and families need in the most effective and efficient manner. Secondly, states should regularly assess the needs of their populations and available resources. Less than one-third of states in this study reported that they conducted needs assessments. With the ACA requirement of data collection and reporting, states should be increasing efforts to establish baseline data and data on outcomes for children based on race/ethnicity and language. States should annually report - state-by-state and county-bycounty on efforts to address disparities using national benchmarks.

Third, it is important to involve stakeholders like youth and family members for policy and program decision making in promoting cultural and linguistic competency in mental health services. Research shows the importance of families and youth service users in their own care management [33]. Therefore, it is important to incorporate youth and family perspectives of diverse background on what kind of service settings would help them access and continue mental health services.

Fourth, states should take advantage of the ACA's effort in cultural competence education and organizational support, provide annual provider training on cultural and linguistic competence, and make these competency-based with adequate funding. While more than half of the states in this study already conducted provider training, only 6 states had competency-based training and one state had training that was tied to certification in cultural and linguistic competence. Further, it is also important to consider different elements of cultural competencies such as communication competencies (e.g. accepted terms of address), staff in culturally acceptable roles, stigma reduction, and friendly milieus for ensuring the quality of culturally and linguistically competence services [32,34-38] in addition to the certification training.

Finally, states should develop and embed anti-stigma strategies in settings that individuals from diverse backgrounds frequent since states report stigma as one of the top gaps in access to mental health services and research shows that stigma reduction is one of the important deterrents to seeking care.

\section{Acknowledgement}

We thank Robyn Gershon, DrPH for helpful comments on the earlier manuscript. This project was funded the John D. \& Catherine T. MacArthur Foundation and the Annie E. Casey Foundation.

\section{References}

1. Howell E, McFeeters J (2008) Children's mental health care: differences by race/ethnicity in urban/rural areas. J Health Care Poor Underserved 19: 237247.

2. Cross T, Bazron B, Dennis K, Isaacs M (1989) Towards a Culturally Competent System of care: A Monograph on Effective Services for Minority Children Who Are Severely Emotionally Disturbed. Georgetown University Child Development Center, Washington, DC.14

3. Brach C, Fraser I, Paez K (2005) Crossing the Language Chasm: An in-depth Analysis of What Language-assistance Programs Look Like in Practice. Health Affairs 24: 424-433.

4. Kataoka SH, Zhang L, Wells KB (2002) Unmet need for mental health care among U.S. children: variation by ethnicity and insurance status. Am J Psychiatry 159: 1548-1555. 
Citation: Cooper JL, Aratani Y (2013) Stalled on the Roadmap? The Status of Cultural and Linguistic Competence-related Policies that Impact Children's Mental Health in the United States. Primary Health Care 3: 143. doi:10.4172/2167-1079.1000143

5. Flores G, Laws M, Mayo S, Zuckerman B, Milagros A, et al. (2003) Errors in medical interpretation and their potential clinical consequences in pediatric encounters. Pediatrics 111: 6-14.

6. Richardson LP, DiGiuseppe D, Garrison M, Christakis DA (2003) Depression in Medicaid-covered youth: differences by race and ethnicity. Arch Pediat Adolesc Med 157: 984-989.

7. Flores G, Tomany-Korman Sc (2008) Racial and Ethnic Disparities in Medical and Dental Health, Access to Care and Use of services in US Children. Pediatrics 121: e286-298.

8. Cooper J (2005) Treatment Patterns for Children with ADHD Enrolled in the Florida Medicaid Program 1996-2001. Doctoral Dissertation, Harvard University.

9. Aratani Y, Cooper JL (2012) Racial and ethnic disparities in the continuation of community-based children's mental health services. J Behav Health Serv Res 39: $116-129$

10. Alegría M, Pérez DJ, Williams S (2003) The role of public policies in reducing mental health status disparities for people of color. Health Aff (Millwood) 22 $51-64$

11. Snowden LR, Masland M, Guerrero R (2007) Federal civil rights policy and mental health treatment access for persons with limited English proficiency. Am Psychol 62: 109-117.

12. Sue S (2006) Cultural Competency: From Philosophy to Research and Practice Journal of Community Psychology 34: 237-245.

13. Hernandez M, Isaacs $M$, Nesman T, Burns D (1998) Perspectives on culturally competent systems of care. In: Hernandez M, Isaacs MR, editors. Promoting Cultural Competence in Children's Mental Health Services. Paul H. Brookes City.

14. Torralba-Romero J (1998) Recruitment, retention, training, and supervision of mental health services staff. In: Promoting Cultural Competence in Children's Mental Health Services (eds. Hernandez, M. \& Isaacs, M.), pp. 81-93. Paul H. Brookes, City.

15. Siegel C, Haugland G, Chambers ED (2003) Performance measures and their benchmarks for assessing organizational cultural competency in behavioral health care service delivery. Adm Policy Ment Health 31: 141-170.

16. Whaley AL, Davis KE (2007) Cultural competence and evidence-based practice in mental health services: a complementary perspective. Am Psychol 62: 563574

17. Betancourt JR, Green AR, Carrillo JE, Ananeh-Firempong O 2nd (2003) Defining cultural competence: a practical framework for addressing racial/ ethnic disparities in health and health care. Public Health Rep 118: 293-302.

18. Cooper L, Powe N (2004) Disparities in Patient Experiences, Healthcare Processes, and Outcomes: The Role of Patient-Provider Racial, Ethnic, and Language Concordance. The Commonwealth Fund, New York.

19. Duffy F, West J, Wilk J, Narrow W, Hales D (2004) Mental Health Practitioners and Trainees. In: Mental Health, United States, 2002, eds. Manderscheid R. \& Henderson M, DHHS: Substance Abuse and Mental Health Services Administration, City.

20. Lurie N, Dubowitz T (2007) Health disparities and access to health. JAMA 297: 1118-1121

21. Probst JC, Laditka SB, Wang JY, Johnson AO (2007) Effects of residence and race on burden of travel for care: cross sectional analysis of the 2001 US National Household Travel Survey. BMC Health Serv Res 7: 40.

22. Flores G, Abreu M, Olivar MA, Kastner B (1998) Access barriers to health care for Latino children. Arch Pediatr Adolesc Med 152: 1119-1125.

23. Pumariega AJ, Rogers K, Rothe E (2005) Culturally competent systems of care for children's mental health: advances and challenges. Community Ment Health J 41: 539-555.
24. Mckay M, Hibbert R, Hoagwood K, Rodriguez J, Murray L, et al. (2004) Integrating evidence-based engagement Interventions into "real world" child mental health settings. Brief Treatment and Crisis Intervention 4: 177-186.

25. Brach C, Fraser I (2000) Can cultural competency reduce racial and ethnic health disparities? A review and conceptual model. Med Care Res Rev 57 Suppl 1: 181-217.

26. Brach C, Paez K, Fraser I (2006) Cultural Competence California Style Agency for Healthcare Research and Quality, Rockville, MD.

27. Omar MA, Green AT, Bird PK, Mirzoev T, Flisher AJ, et al. (2010) Mental health policy process: a comparative study of Ghana, South Africa, Uganda and Zambia. Int J Ment Health Syst 4: 24.

28. Behar LB (2003) Using litigation to improve child mental health services: promises and pitfalls. Adm Policy Ment Health 30: 199-218.

29. Knitzer J (1982) Unclaimed Children: The Failure of Public Responsibility to Children and Adolescents in Need of Mental Health Services. Children's Defense Fund, Washington, DC.

30. Min LR (2009) Reading Between the Lines: Medicaid, Early Periodic Screening Diagnosis and Treatment, and Section 1983. Seattle Journal for Social Justice 7: 737-761.

31. Andrulis DP, Siddiqui NJ, Purtle J, Duchon L (2010) Patient Protection and Affordable Care Act of 2010: Advancing health equity for racially and ethnically diverse populations. Washington, D.C.: Joint Center for Political and Economic Studies.

32. Office of Minority Health, U.S. Department of Health and Human Service (2013) National Standards for Culturally and Linguistically Appropriate Services in Health and Health Care: A Blueprint for Advancing and Sustaining CLAS Policy and Practice. Washington, DC

33. Cooper J, Aratani Y, Knizter J, Douglas-Hall A, Dababnah S, et al (2008) Unclaimed Children Revisited: The Status of Children's Mental Health Policy in the United States. National Center for Children in Poverty, Columbia University Mailman School of Public Health, New York.

34. Siegel C, Haugland G, Reid-Rose L, Hopper K (2011) Components of cultural competence in three mental health programs. Psychiatr Serv 62: 626-631.

35. Dawes DE (2010) The Health Equity Provisions in the Health Reform Law. Premier Healthcare Alliance, Washington, DC.

36. Harper M, Hernandez M, Nesman T, Mowery D, Worthington J, et al. (2006) Organizational Cultural Competence: A Review of Assessment Protocols. University of South Florida, Louis de la Parte Mental Health Institute, Research \& Training Center for Children's Mental Health, Tampa, FL.

37. National Technical Assistance Center for State Mental Health Planning (Ntac) (2004) Cultural Competency: Measurement as a Strategy for Moving Knowledge into Practice in State Mental Health Systems. National Association of State Mental Health Program Directors, Alexandria, Virginia.

38. Mills C, Stephan SH, Moore E, Weist MD, Daly BP, et al. (2006) The President's New Freedom Commission: capitalizing on opportunities to advance schoolbased mental health services. Clin Child Fam Psychol Rev 9: 149-161. 